\title{
The Influence of Interference Layer on the Prediction of Seismic Information of Channel Sedimentary Reservoir
}

\author{
Xiangsheng Bao $\mathbb{D}^{1,2}$ Zhanhu Cai $\mathbb{D}^{1,2}$ Qingzhen Wang $\mathbb{D}^{1}{ }^{1}$ Junfeng Yu $\mathbb{1},{ }^{1,2}$ \\ and Yecheng $\mathrm{Li} \mathbb{D i D}^{1,2}$ \\ ${ }^{1}$ National Engineering Laboratory for Offshore Oil Exploration, Beijing 100028, China \\ ${ }^{2}$ Guangdong University of Petrochemical Technology, Maoming, Guangdong 525000, China \\ Correspondence should be addressed to Xiangsheng Bao; baoxsh@gdupt.edu.cn
}

Received 3 November 2021; Accepted 27 December 2021; Published 28 January 2022

Academic Editor: Xiao Wang

Copyright (c) 2022 Xiangsheng Bao et al. This is an open access article distributed under the Creative Commons Attribution License, which permits unrestricted use, distribution, and reproduction in any medium, provided the original work is properly cited.

\begin{abstract}
Channel sedimentary reservoirs are the main oil and gas accumulation sites at home and abroad. With the deepening of oil and gas exploration, channel-related oil and gas reservoirs with obvious seismic characteristics have been mostly discovered, and the rest are basically oil and gas reservoirs with unobvious seismic characteristics and difficult to be discovered. The difficulty and risk of discovering these oil and gas reservoirs are on the increase. In order to reduce the exploration risk, it is necessary to form a more reliable time window control theory with a better seismic interpretation technique for channel reservoir reliability. In this paper, 2D forward modeling was used to study the influence of the upper and lower interference layers on the imaging of channel reservoir. When the lithological composition is relatively stable, the degree of interference of the interference layer is closely related to the seismic wavelet, and it is especially susceptible to the main frequency of the seismic wavelet. The lower the main frequency of seismic wavelet, the greater the degree of interference of interference layers on the imaging of channel reservoir, and vice versa. Further analysis on the characteristics of the Ricker wavelet was made and showed that the influence of the upper and lower interference layers on the imaging information of the channel reservoir is concentrated in half apparent major period. Then, considering the dynamic change of distance between the interference layers and the top and bottom interfaces of channel reservoir, the influence of interference layers on the imaging of channel reservoir was studied through 1D forward modeling. The interference area was divided into maximum interference area and main interference area depending on the degree of influence. On this basis, the time window control theory of channel reservoir prediction was clarified. The seismic information which reflects the channel reservoir reliably can be obtained by avoiding the maximum interference area, especially the main interference area.
\end{abstract}

\section{Introduction}

Channel sedimentary reservoirs are the main oil and gas accumulation sites at home and abroad [1]. Many world-renowned oilfields, such as Bolivar Oilfield in Venezuela, Burgess Oilfield in the Persian Gulf, Frio Oilfield in Texas, USA, Groningen Oilfield in the Netherlands, and Sz36-1 Oilfield in the Bohai Sea, China $[1,2]$, are giant oilfields related to channel sedimentary reservoirs. With the deepening of onshore and offshore oil and gas exploration in China, channel-related oil and gas reservoirs with obvious seismic characteristics have been mostly discovered, and the rest are basically oil and gas reservoirs with unobvious seismic characteristics and difficult to be discovered. The difficulty and risk of discovering these oil and gas reservoirs are on the increase. In order to reduce oil and gas exploration risk, a seismic interpretation technique for channels with better channel identification ability and accuracy is required. At present, many seismic interpretation techniques have been applied to identify channels. Wescott et al. [3] used the interpretation technique based on amplitude strength to identify river channels. Xu et al. [4], Zhang et al. [5], and Fan et al. [6] used the interpretation technique based on the attributes of the waveform structure to identify river channels. Liu et al. and Zhou et al. used the coherence technique $[7,8]$ 
and the curvature attribute interpretation technique [8] to identify channels. Ray et al. [9] and Wang et al. [10] used the spectral decomposition-based interpretation technique to identify channels. Yang et al. [11] and Li Nan et al. [12] used the interpretation technique based on multiattribute fusion to identify channels. Song [13] used the poststack wave impedance inversion interpretation technique to identify channels. Bao et al. [14] and Jiang Yong et al. [15] used the prestack inversion interpretation technique to identify channels.

Although various river channel seismic interpretation technologies have been formed [3-15], they are divided into two categories based on the perspective of seismic wavelet. One is seismic attribute analysis techniques, such as amplitude strength-based interpretation technique, interpretation technique based on waveform structural properties, coherence technique, and curvature attribute interpretation technique. The other is elastic parameter inversion techniques, such as poststack wave impedance inversion interpretation technique and prestack inversion interpretation technique. From the perspective of the application width of existing techniques, the seismic attribute analysis technique is now the mainstream seismic interpretation technique for channels. Compared with the elastic parameter inversion technology, the seismic attribute analysis technology has two advantages. First, there is no need to remove the seismic wavelet, which avoids the error caused by the inaccurate acquisition of the seismic wavelet. Second, the differences in the structure and thickness of formation are included, which is conducive to a better interpretation of channels. However, with the continuous application of seismic attribute analysis technology in river channel interpretation and the increasing difficulty in the discovery of channel-related oil and gas reservoirs, it is gradually realized that, to improve the application of seismic attribute analysis techniques in channel interpretation, it is necessary to carefully study how to control the key link of analysis time window that restricts the accuracy of river channel interpretation. So far, some scholars have expressed their own opinions on the analytical time window. Yang et al. [16] proposed that the determination of time window size should depend on the apparent period $(T)$ of seismic reflection waves and the size of geological body of the study area. Zhu Chao et al. [17] suggested that the time window size should be more than half a phase and less than $150 \mathrm{~ms}$. Zhang et al. [3] proposed the time window size as one period. The above viewpoints show that the scholars engaged in channel interpretation research have realized the importance of time window to channel interpretation. However, it is difficult to apply and popularize the time window, which is now an experience without strict theoretical derivation in practice. In this paper, a time window control theory of channel interpretation, which is easy to generalize, was developed based on the construction of $2 \mathrm{D}$ channel model so as to promote the improvement of channel interpretation techniques in China.

\section{Construction of 2D Channel Model}

Suitable models are the basis and guarantee for the proposal of theories. In real world, sediments appear in both single and composite channels, wide and narrow channels, and channels with good and poor sand body development. Therefore, different channels should be taken into consideration during the construction of channel model so that the time window control theory can be better adaptable in the application of actual diverse river channel interpretation.

Based on the geological conditions of the Sz36-1 Oilfield, which is located in the Dongying formation of China's Bohai Bay basin, a two-dimensional channel geological model is constructed as shown in Figure 1. The model (Figure 1) included three layers: the upper overburden layer (light gray area in Figure 1), the middle target layer (dark gray area containing the channel in Figure 1), and the lower sedimentary layer (dark green area in Figure 1). The target layer in Figure 1 included seven channel sedimentary sand bodies (referred to as channel sand bodies), which were numbered as (1), (2), (3), (4), (5), (6), and (7), respectively. According to the principle of burial depth similarity in Figure 1, (1)-(5) belonged to the late channel sediments, while (6)-(7) belonged to the early channel sediments. Based on the analysis of the thickness of different channel sediments, (2), (3), (5), (6), and (7) were developed, while (1) and (4) were undeveloped. According to the relative width of channel sand bodies, (5) was the widest, while (1) and (3) were narrow. The constructed 2D channel geological model 2 (Figure 2) included three layers, which was the same as Figure 1, but there are differences in the upper overburden layer; the upper overburden layer in Figure 2 had three brown sand bodies, which were numbered as upper (1), upper (2), and upper (3), respectively.

The constructed 2D channel geological model 3 (Figure 3) included three layers, which was the same as Figure 1. But the lower sedimentary layer in Figure 3 had three brown sand bodies, which were numbered as lower (1), lower (2), and lower (3), respectively.

In Figures 1, 2, and 3, light gray, dark gray, and dark green indicated different mudstones, while brown and yellow indicated different sandstones. Longitudinal wave velocities and densities vary among different mudstones and sandstones. The longitudinal wave velocities of different mudstones and sandstones were set according to the data in Zhao's scientific research report [2]. Table 1 shows the longitudinal wave velocities of different mudstones and sandstones. Gardner formula is used to calculate the longitudinal wave densities of different lithology.

Figures 1, 2, and 3 provide a basic model for the research of time window control theory of channel interpretation. Researchers interested in this paper can also set up their own models, but their understanding based on model study will not contradict this paper.

\section{Synthetic Seismic Records at Different Frequencies}

To study the influence of different interferences on the imaging of channel reservoir, the synthetic seismic records of different 2D channel geological models in Figures 1, 2, and 3 at different main frequencies of seismic wavelet were obtained using the Ricker wavelet. Figure 4 is the synthetic seismic records of different $2 \mathrm{D}$ channel geological models at 


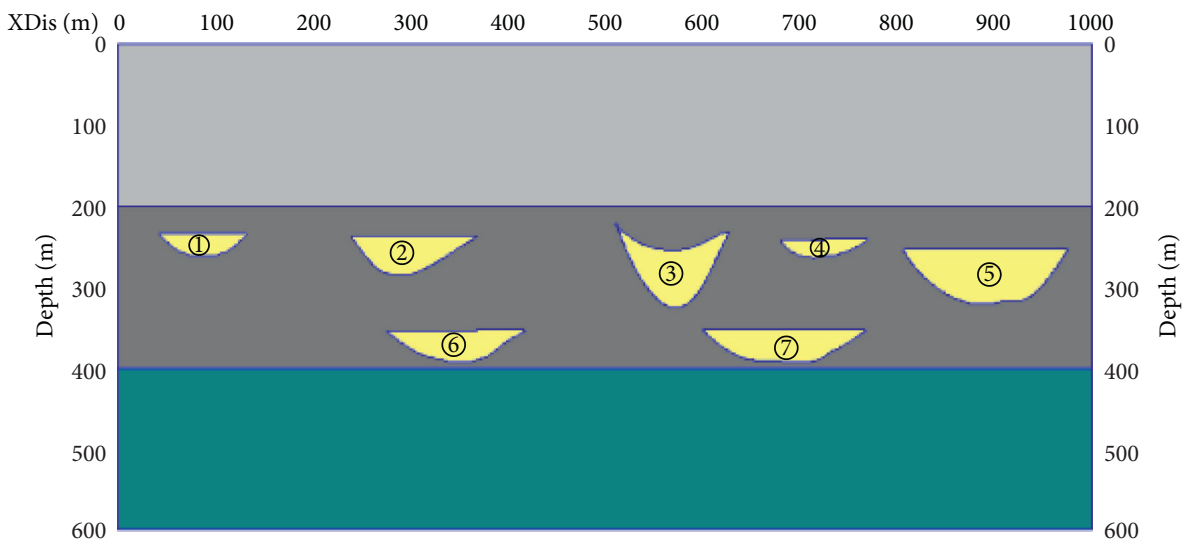

FIGURE 1: 2D channel geological model with noninterference.

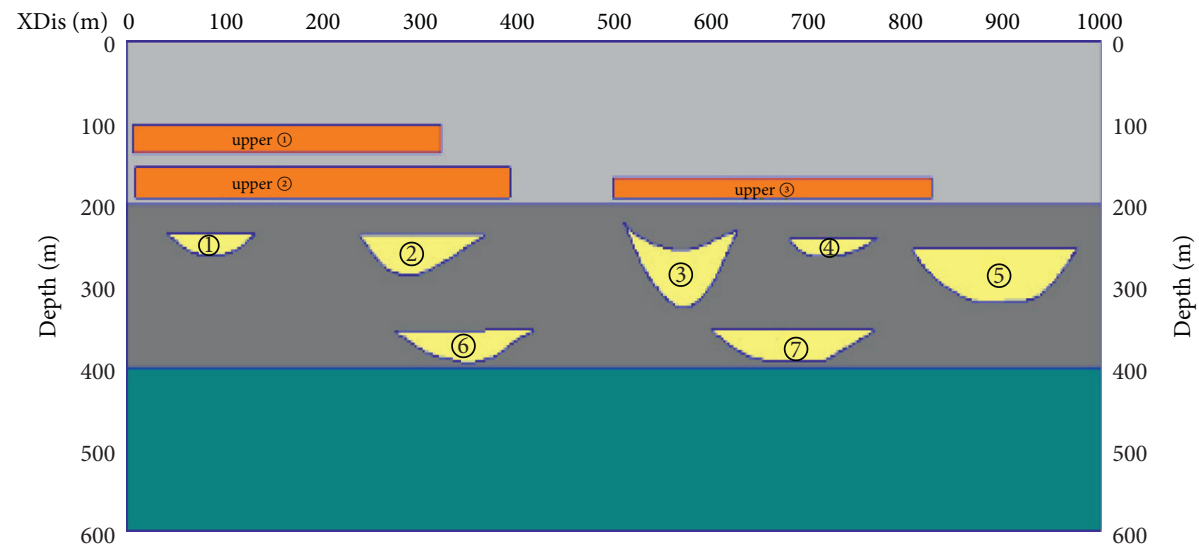

FIGURE 2: 2D channel geological model with upper interference.

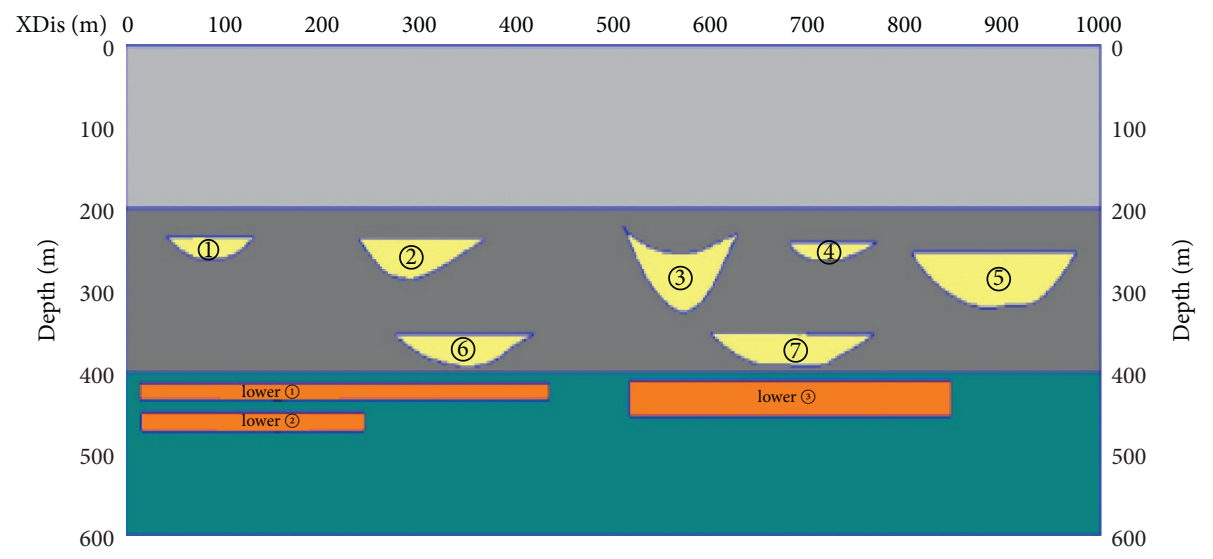

FIGURE 3: 2D channel geological model with lower interference.

TABLE 1: Longitudinal wave velocities of different mudstones and sandstones.

\begin{tabular}{lccccc}
\hline Lithology & Gray mudstone & Dark mudstone & Dark green mudstone & Brown sandstone & Yellow sandstone \\
\hline Velocity $(\mathrm{m} / \mathrm{s})$ & 2700 & 2800 & 2900 & 2650 & 2600 \\
\hline
\end{tabular}

$20 \mathrm{~Hz}$. The comparison among Figures 4(a), 4(b), and 4(c) showed that when there was an upper interference, the imaging of synthetic seismic records of upper channel reservoir was affected; when there was a lower interference, the imaging of synthetic seismic records of lower channel reservoir was affected. Figure 5 and 6 are the synthetic 


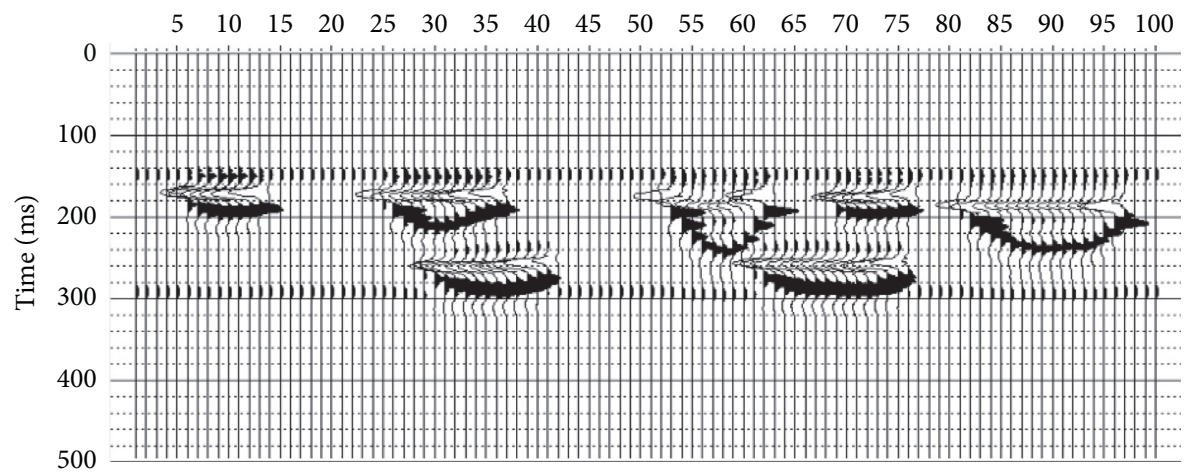

(a)

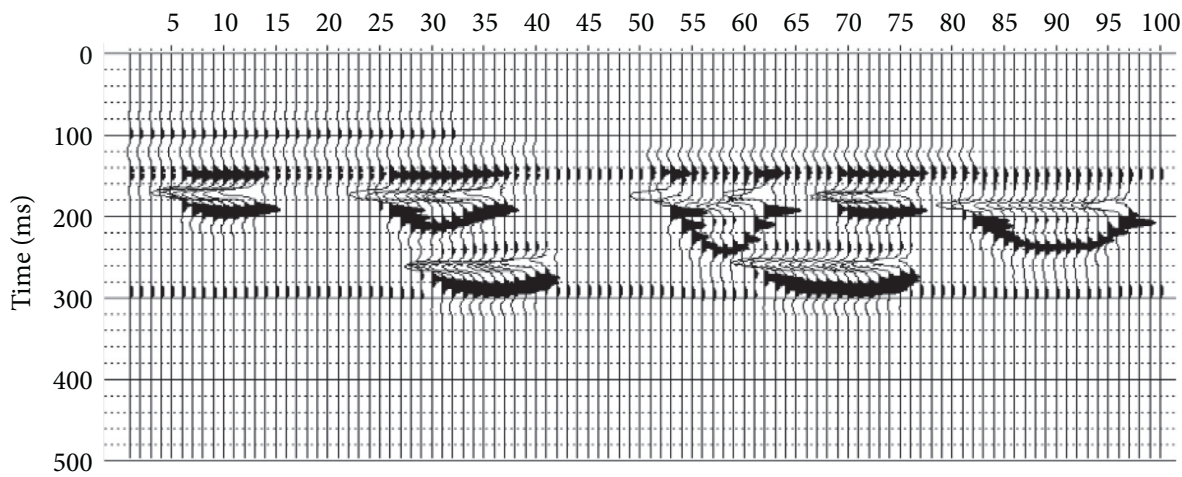

(b)

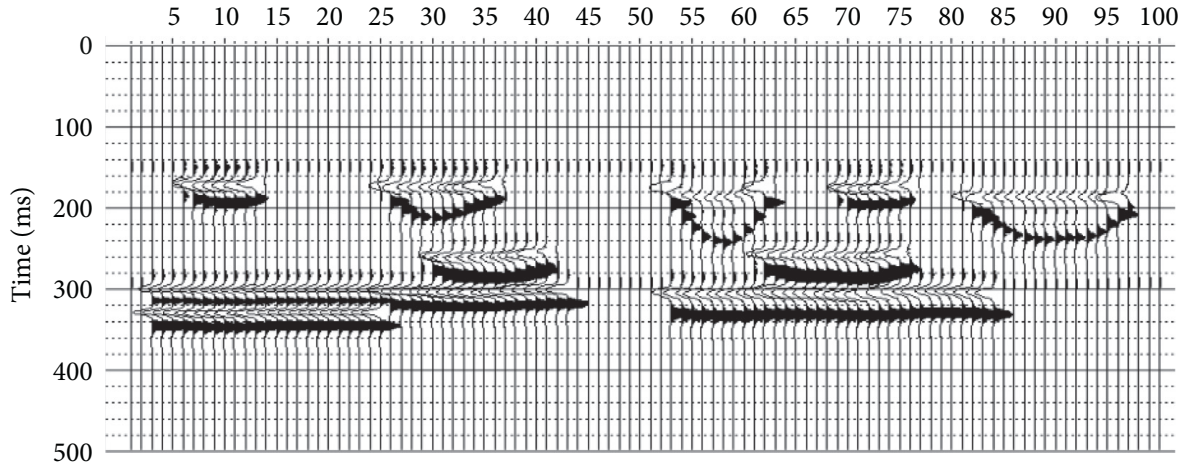

(c)

Figure 4: Synthetic seismic records of different 2D channel geological models at $20 \mathrm{~Hz}$. (a) Noninterference. (b) Upper interference. (c) Lower interference.

seismic records of different $2 \mathrm{D}$ channel geological models at $30 \mathrm{~Hz}$ and $40 \mathrm{~Hz}$, respectively. The comparison among Figures 5(a), 5(b), and 5(c) as well as Figures 6(a), 6(b), and 6(c) showed that the influence of different interferences on the imaging of synthetic seismic records of channel reservoir was similar to that in Figures 4(a), 4(b), and 4(c).

\section{Influence Range of the Upper and Lower Interference Layers on the Channel Reservoir}

The waveforms were extracted from Figures 4(a), 4(b), 5(a), 5(b), 6(a), and 6(b) at 10-channel intervals and placed together for comparison display (Figure 7). The black waveforms in Figures 7 and 8 were the waveforms of channel reservoirs with noninterference. The blue waveform in Figure 7 and the red waveform in Figure 8 were those with upper and lower interferences, respectively. The red line in Figure 7 indicates the bottom position of the channel reservoir where there are obvious imaging differences when there is upper interference in the channel reservoir. The comparison among Figures $7(\mathrm{a}), 7(\mathrm{~b})$, and $7(\mathrm{c})$ indicated that the red line gradually moved upward from Figure 7 (a) to Figure $7(\mathrm{c})$. The blue line in Figure 8 was the top where significant imaging differences were visible within the channel reservoir with lower interference. And the comparison among Figures 8(a), 8(b), and 8(c) suggested that the blue line gradually moved downward from Figure $8(\mathrm{a})$ to Figure 8(c). 


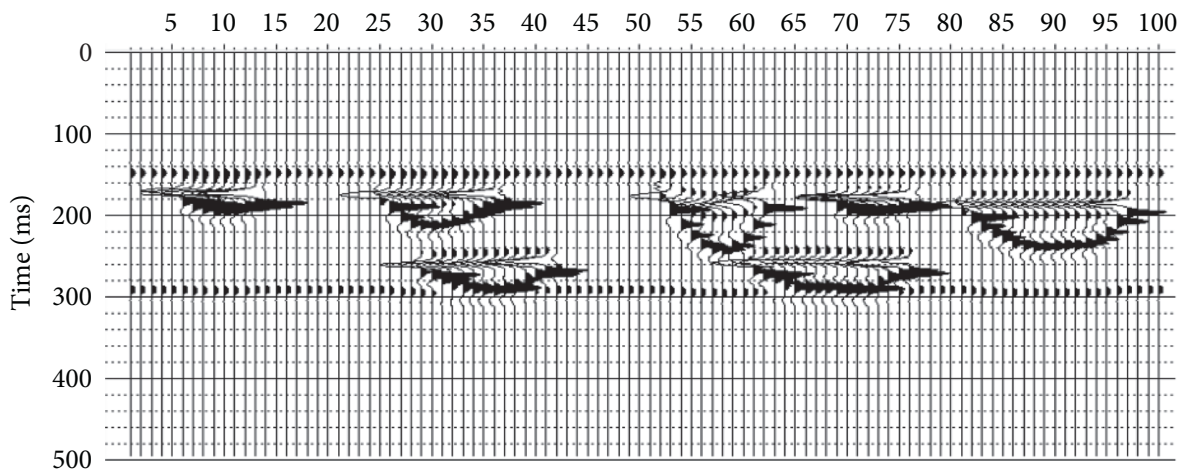

(a)

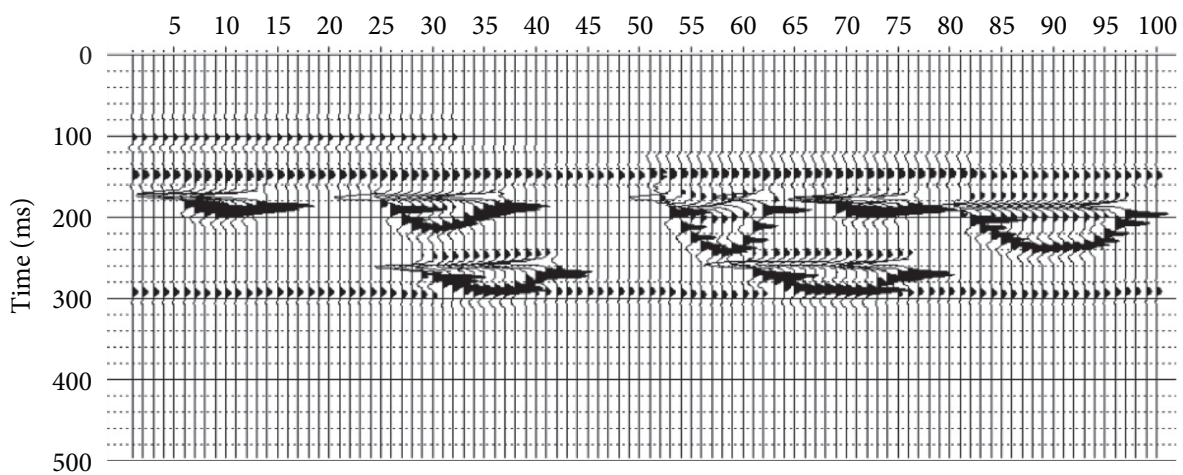

(b)

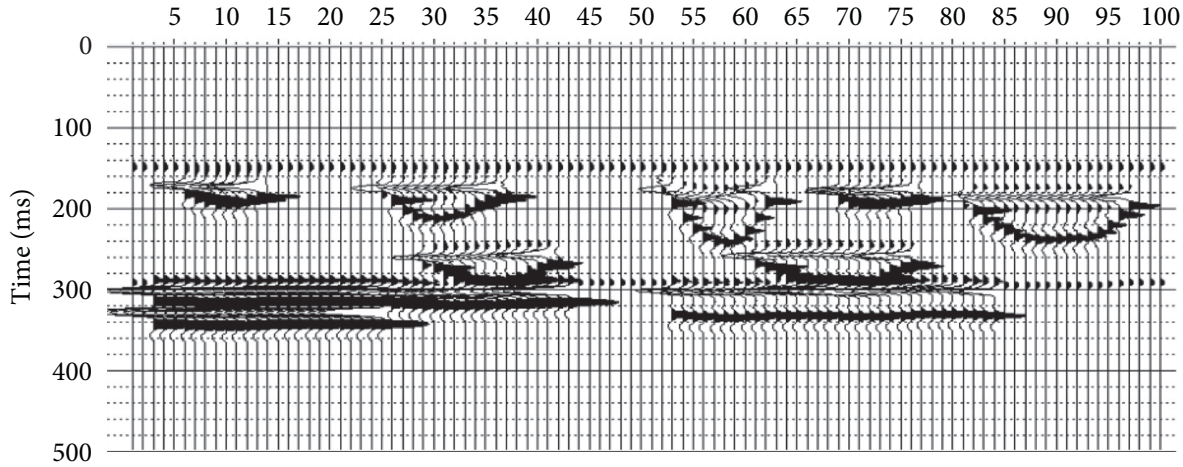

(c)

FIGURE 5: Synthetic seismic records of different 2D channel geological models at $30 \mathrm{~Hz}$. (a) Noninterference. (b) Upper interference. (c) Lower interference.

It can be seen from Figures 7 and 8 that the higher the main frequency of the Ricker wavelet, the smaller the interference range of interference layers on the internal imaging of channel reservoir with an upper interference layer and lower interference layer. It shows that the internal imaging difference of the channel reservoir caused by the interference layer is related to the seismic wavelet. Analysis of the relationship between the influence of interference layers on the internal imaging of channel reservoir and the seismic wavelet should start from seismic records. When the seismic wavelet enters into a certain reflection to form a seismic reflection, it can be regarded as the convolution of the reflection coefficient and the seismic wavelet with only one interface underground. Thus, the influence of interference layers on the imaging of channel reservoir with upper and lower interference layers is determined by the seismic wavelet and reflection coefficient. The reflection coefficients of formations near a regional reservoir are generally very close unless there is a special high-speed rock stratum or low-speed rock stratum. Therefore, the influence of interference layers on the imaging of channel reservoir is mainly determined by the seismic wavelet. Study on the seismic wavelet characteristics is critical to the analysis of the influence of seismic wavelet on the channel reservoir. The Ricker wavelet, a seismic wavelet, was used in this paper. Its expression is shown in,

$$
R(t)=\left[1-2(\pi f t)^{2}\right] e^{\left[-(\pi f t)^{2}\right]},
$$




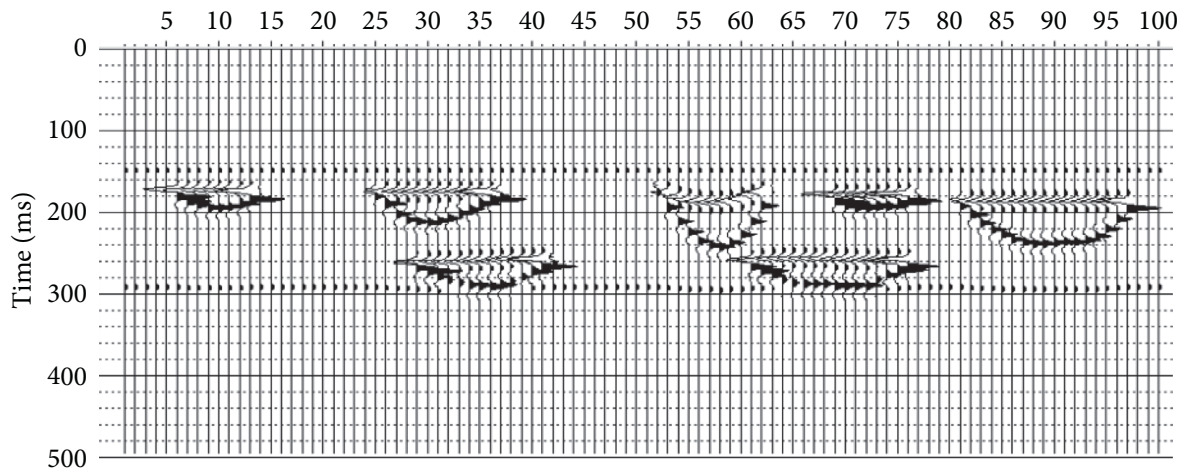

(a)

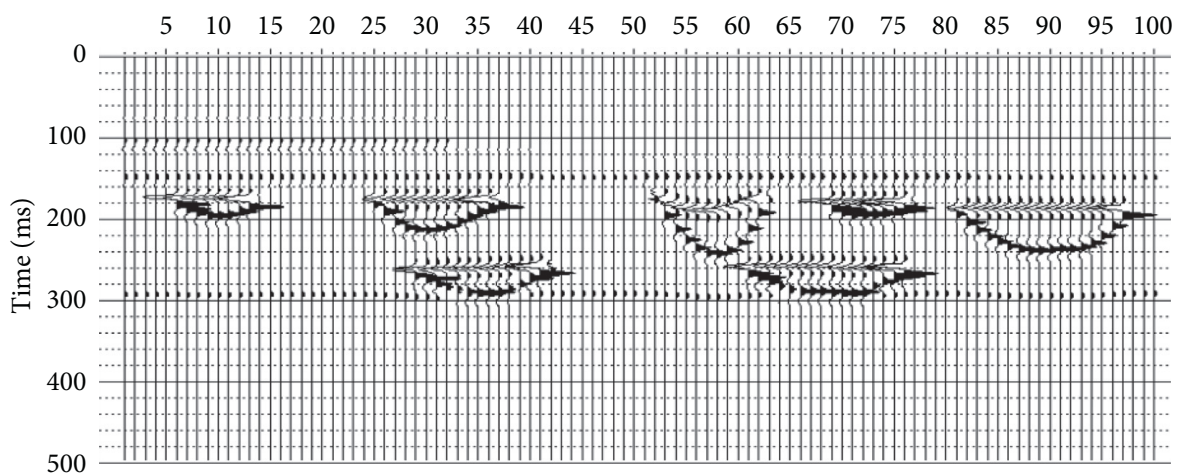

(b)

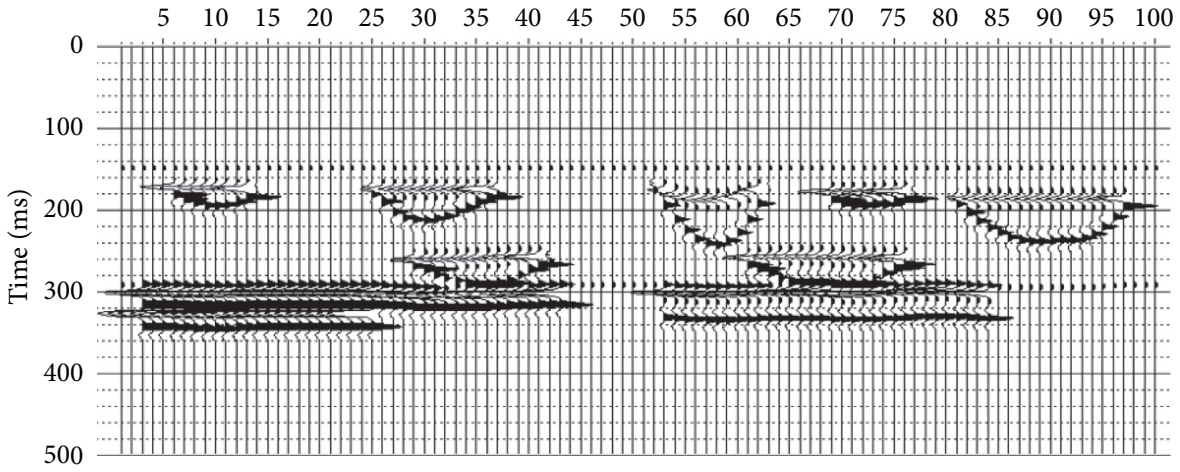

(c)

FIGURE 6: Synthetic seismic records of different 2D channel geological models at $40 \mathrm{~Hz}$. (a) Noninterference. (b) Upper interference. (c) Lower interference.

where $t$ is the time, unit: $s$; $f$ is the dominant frequency, unit: $H Z ; R(t)$ is the amplitude value of Ricker wavelet.

The characteristics of the Ricker wavelet were analyzed in the following to find out the differences in the imaging of the channel reservoir. The Ricker wavelet is an infinite long aperiodic signal symmetric at $0 \mathrm{~ms}$. Technically, the reflection of all interfaces will form interferences, which differ only in size. However, a study using the Ricker wavelet is not of much help in practice. The Ricker wavelet energy is mainly concentrated around $0 \mathrm{~ms}$, and the bilateral energy is approximately approaching 0 . The characteristics of the Ricker wavelet were analyzed in the following.
4.1. Zero-Value Points. Let $R(t)=0$; then set $R(t)=0$;

$$
\begin{aligned}
{\left[1-2(\pi f t)^{2}\right] e^{\left[-(\pi f t)^{2}\right]} } & =0 \\
{\left[1-2(\pi f t)^{2}\right] } & =0 \\
t & = \pm \frac{1}{\sqrt{2} \pi f} .
\end{aligned}
$$

The time corresponding to the zero-value points of the Ricker wavelet at different main frequencies was obtained by (2) (see Table 2). 


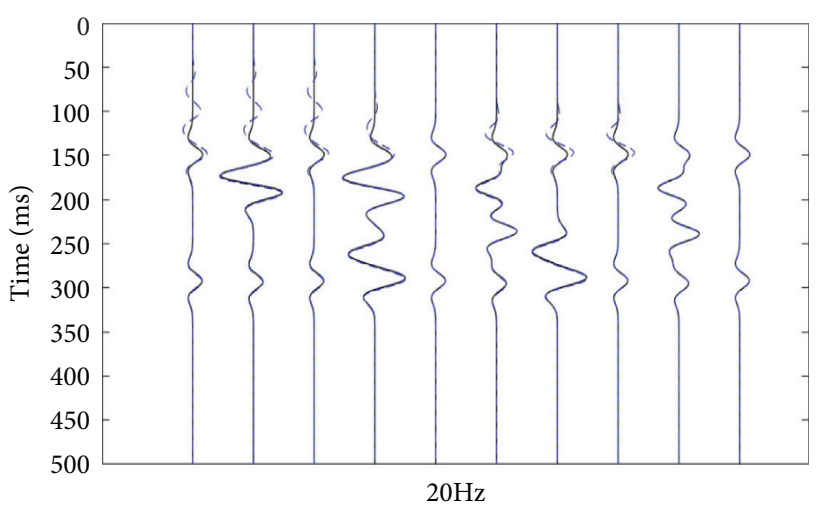

(a)

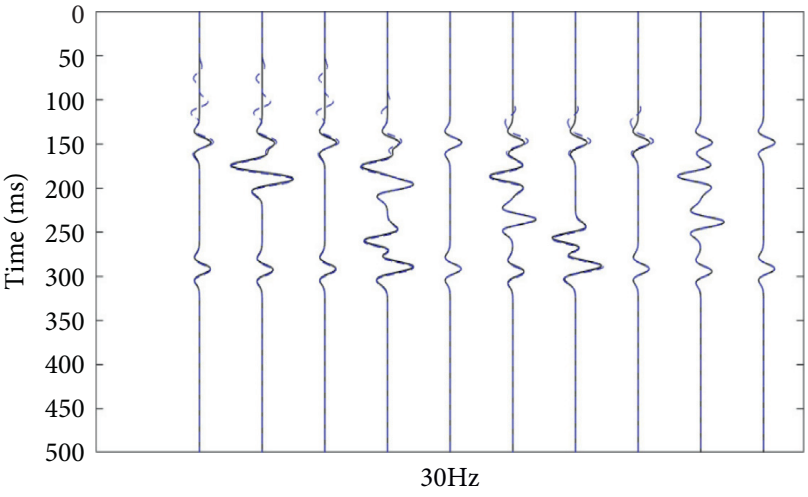

(b)

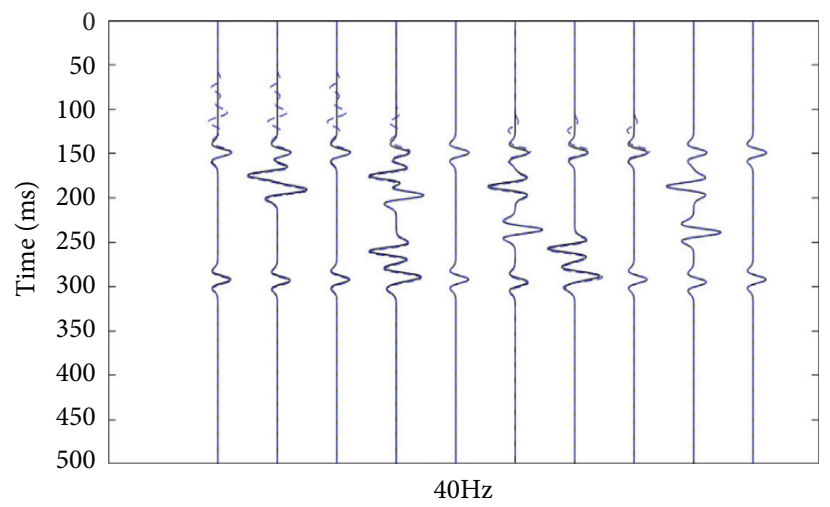

(c)

Figure 7: Comparison of waveforms of channel reservoirs with upper interference and noninterference at different frequencies. (a) $20 \mathrm{~Hz}$. (b) $30 \mathrm{~Hz}$. (c) $40 \mathrm{~Hz}$.

4.2. Extreme Value Points. Three extreme value points of the Ricker wavelet were obtained by taking their derivatives.

Set $R_{I}(t)=0$; then,

$$
\begin{aligned}
{\left[1-2(\pi f t)^{2}\right]^{\prime} e^{-(\pi f t)^{2}}+\left[1-2(\pi f t)^{2}\right]\left[e^{-(\pi f t)^{2}}\right]^{\prime} } & =0, \\
-4(\pi f)^{2} t e^{-(\pi f t)^{2}}+\left[1-2(\pi f t)^{2}\right] e^{-(\pi f t)^{2}}\left(-2(\pi f)^{2} t\right) & =0, \\
\left(-6+4(\pi f t)^{2}\right)(\pi f)^{2} t e^{-(\pi f t)^{2}} & =0 .
\end{aligned}
$$

By solving the equation, there were three values about $t$ making the equation equal to 0 ; that is, $t_{1}=0, t_{2}=\sqrt{3 / 2}(1 / \pi f), t_{3}=-\sqrt{3 / 2}(1 / \pi f)$. The time corresponding to the extreme value points of the Ricker wavelet at different main frequencies was obtained (see Table 3).

4.3. Period. The time interval between the adjacent maximum (or minimal) values in the vibration graph of wave was commonly known as the apparent period [18]. According to the method to solve the extreme value points of the Ricker wavelet, the apparent period (expressed in $P_{A}$ ) of the Ricker wavelet can be calculated using the time interval between the two wave troughs by,

$$
P_{A}=\frac{\sqrt{6}}{\pi f} \approx \frac{0.780}{f}(\mathrm{~s})=\frac{780}{f}(\mathrm{~ms}) .
$$

$f$ in (1) is usually the main frequency, to which the period corresponded is the main frequency period (expressed as $P_{M F}$ ):

$$
P_{M F}=\frac{1}{f}(\mathrm{~s})=\frac{1000}{f}(\mathrm{~ms}) .
$$

A periodic signal has a fixed period. However, the Ricker wavelet, a nonperiodic signal with an infinite long signal, does not have a fixed period. But for the need of research, concepts of period like period signal need to be introduced. To distinguish from the period of periodic signal, the concept of the apparent major period (expressed as $P_{A M}$ ) was introduced here. When the amplitude absolute value of the Ricker wavelet gradually tended towards 0 from both sides, it reached the absolute value of the difference between the two time points at the maximum amplitude of $1 \%$. Table 4 and Figure 9 show the values corresponding to the apparent period, main frequency period, apparent major period at different main frequencies, and the change relations between the three periods and the main frequencies. It can be concluded that apparent period $<$ main frequency period < apparent major period; that is, $P_{A}<P_{M F}<P_{A M}$.

To better analyze the Ricker wavelet, a Ricker wavelet at $20 \mathrm{~Hz}$ was explained in the following. Figure 10 is a Ricker wavelet at $20 \mathrm{~Hz}$ with a time range of [ $-65 \mathrm{~ms}, 65 \mathrm{~ms}$ ]. As can be seen from Figure 10, the Ricker wavelet took the 


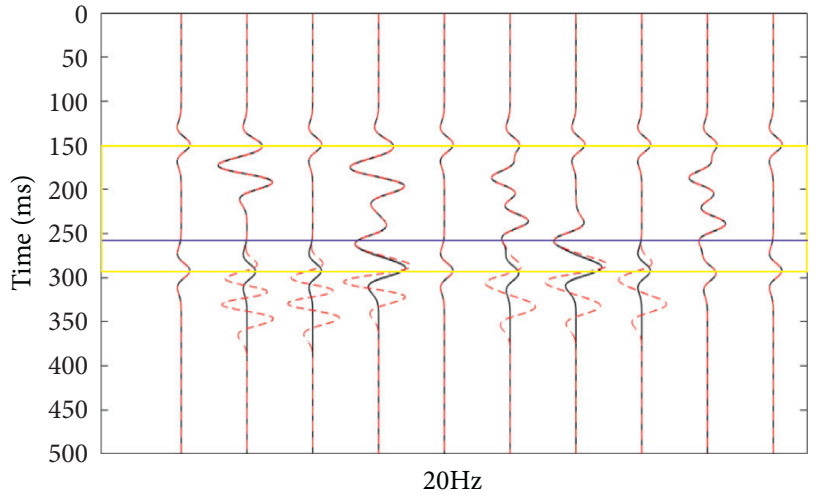

(a)

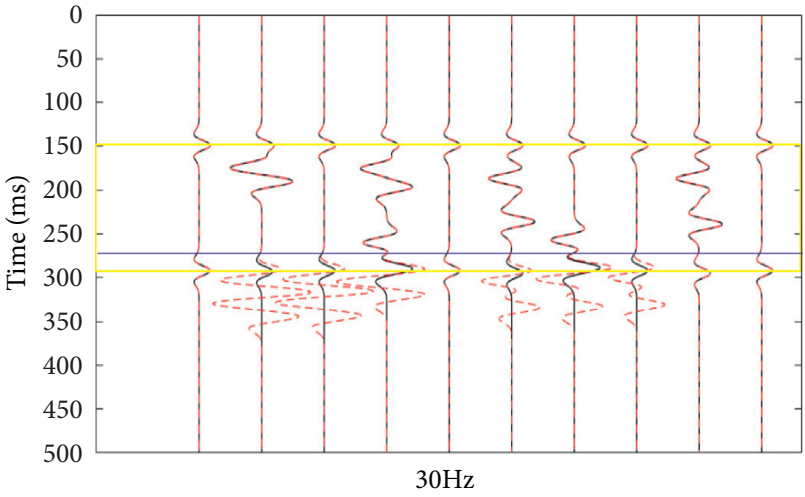

(b)

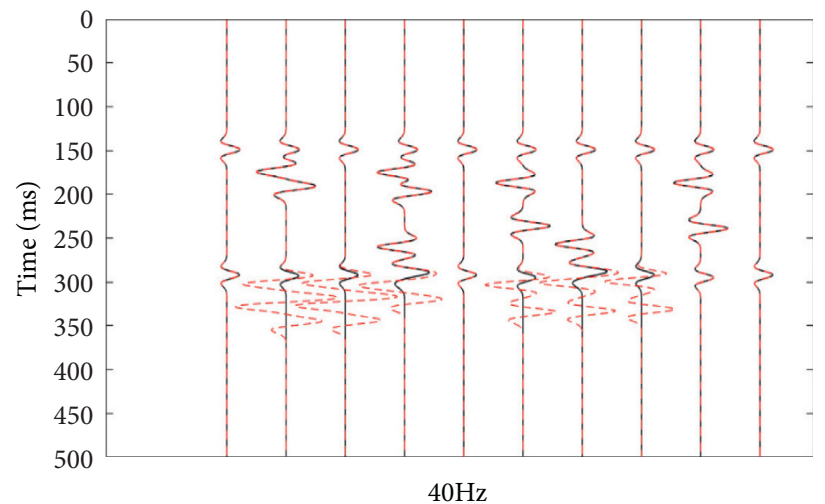

(c)

FiguRE 8: Comparison of waveforms of channel reservoirs with lower interference and noninterference at different frequencies. (a) $20 \mathrm{~Hz}$. (b) $30 \mathrm{~Hz}$. (c) $40 \mathrm{~Hz}$.

TABle 2: Time corresponding to the zero-value points of the Ricker wavelet at different main frequencies.

\begin{tabular}{lccccccccc}
\hline Main frequency $(\mathrm{Hz})$ & & 15 & 20 & 25 & 30 & 35 & 40 & 45 & 50 \\
\hline \multirow{2}{*}{ The time corresponding to the zero-value points $(\mathrm{ms})$} & $>0$ & 15.01 & 11.25 & 9.00 & 7.50 & 6.43 & 5.63 & 5.00 & 4.50 \\
& $<0$ & -15.01 & -11.25 & -9.00 & -7.50 & -6.43 & -5.63 & -5.00 & -4.50 \\
\hline
\end{tabular}

TABLE 3: Time corresponding to the extreme value points of the Ricker wavelet at different main frequencies.

\begin{tabular}{|c|c|c|c|c|c|c|c|c|c|}
\hline Main frequency $(\mathrm{Hz})$ & & 15 & 20 & 25 & 30 & 35 & 40 & 45 & 50 \\
\hline \multirow{3}{*}{ The time corresponding to the extreme value points (ms) } & $>0$ & 25.99 & 19.49 & 15.59 & 12.99 & 11.14 & 9.75 & 8.66 & 7.80 \\
\hline & 2 & 0.00 & 0.00 & 0.00 & 0.00 & 0.00 & 0.00 & 0.00 & 0.00 \\
\hline & $<0$ & -25.99 & -19.49 & -15.59 & -12.99 & -11.14 & -9.75 & -8.66 & -7.80 \\
\hline
\end{tabular}

TABLE 4: Values corresponding to the apparent period, main frequency period, apparent major period at different main frequencies.

\begin{tabular}{lcccccccc}
\hline Main frequency $(\mathrm{Hz})$ & 15 & 20 & 25 & 30 & 35 & 40 & 45 & 50 \\
\hline Apparent period & 52.00 & 39.00 & 31.20 & 26.00 & 22.29 & 19.50 & 17.33 & 15.60 \\
Main frequency period & 66.67 & 50.00 & 40.00 & 33.33 & 28.57 & 25.00 & 22.22 & 20.00 \\
Apparent major period & 115.00 & 87.00 & 71.00 & 59.00 & 51.00 & 45.00 & 39.00 & 37.00 \\
\hline
\end{tabular}

maximum positive value at the zero-value point, then gradually decreased to the maximum negative value to the sides, and finally gradually increased to the sides. The analysis of the zero-value points of the Ricker wavelet showed that the Ricker wavelet had only two zero-value points. So when the Ricker wavelet increased from the wave trough, the amplitude can only be infinitely approaching but not reaching 0 . The analysis of the extreme value point of the Ricker wavelet suggested that the Ricker wavelet had three extreme value points, including one peak value point and 


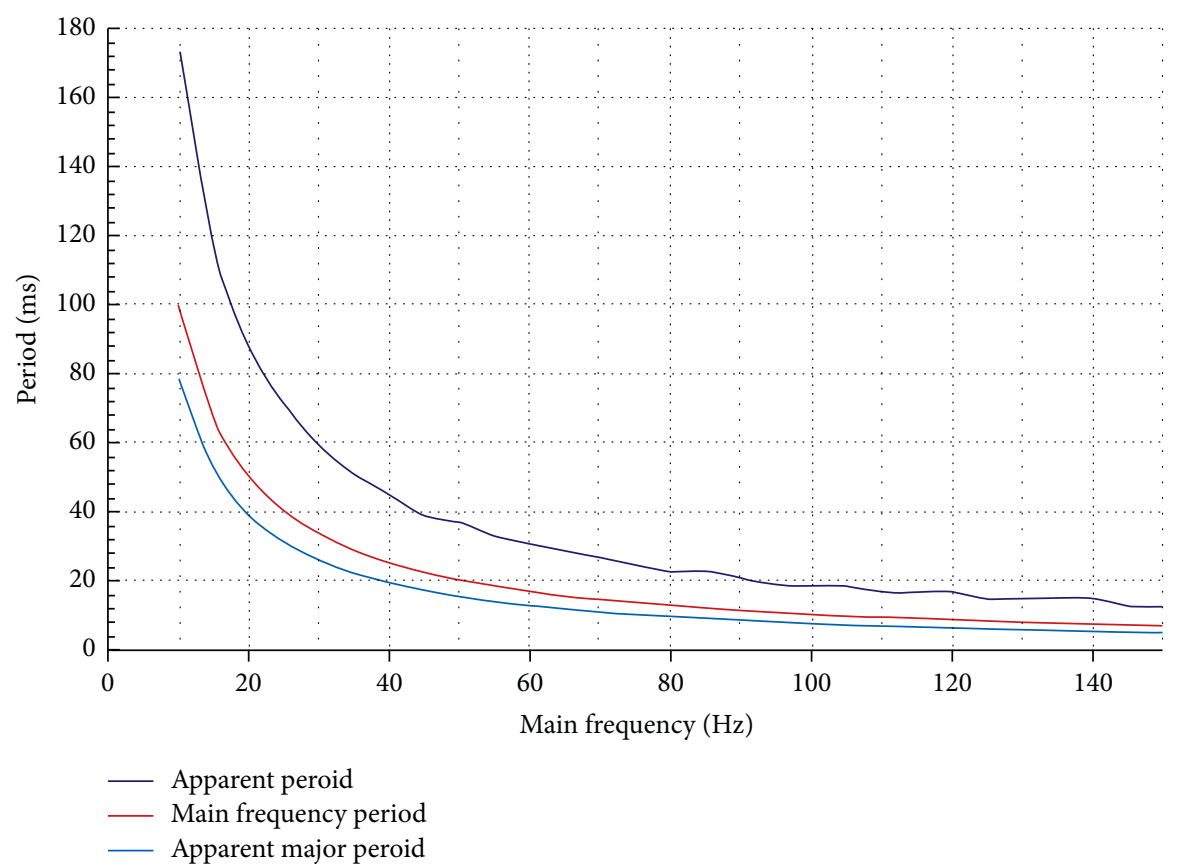

Figure 9: Change relations between the three periods and the main frequencies.

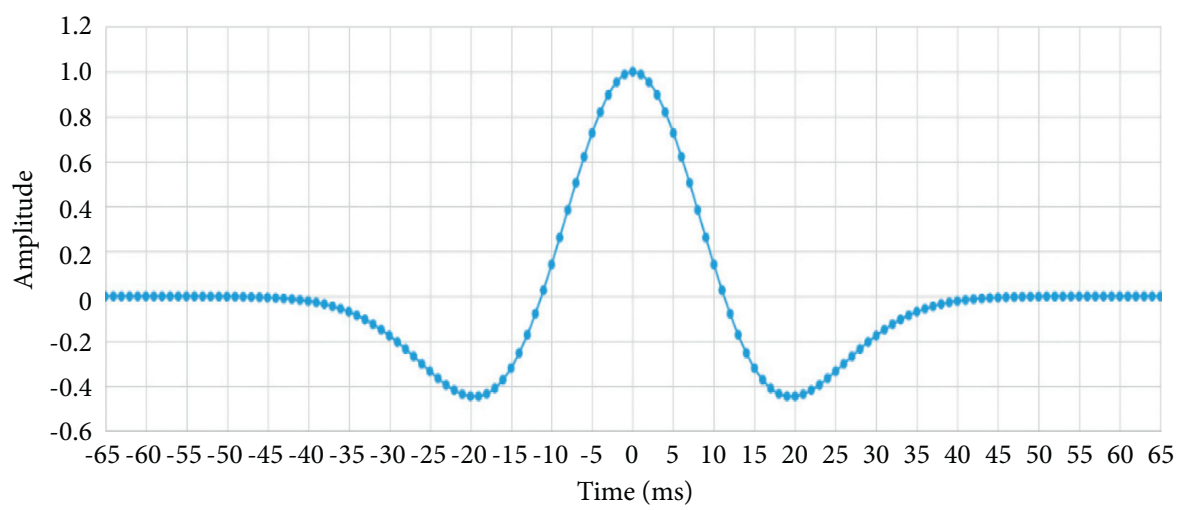

Figure 10: Ricker wavelet at $20 \mathrm{~Hz}$.

two trough value points, as shown in Figure 10. The amplitude absolute value at the trough value point was about over $40 \%$ of that at the peak value point.

As the study of Ricker wavelet showed, the wavelet was infinitely long, and the amplitude was only zero at two zerovalue points. In this way, the Ricker wavelet influences the channel reservoir at almost all locations. Further analysis of the Ricker wavelet showed that since there are large amplitudes on both sides of the zero points and trough points, even more than $40 \%$ of the maximum amplitude, the influence on the reservoir imaging information of both sides of them cannot be ignored. By contrast, the proposed apparent major period, with amplitudes on both sides less than $1 \%$ of the maximum amplitude, was negligible for its influence. Based on the analysis, half of the apparent period (PAM) was considered as the main influence radius of the Ricker wavelet on the channel reservoir.

\section{Time Window Control Theory of Channel Interpretation}

The average amplitude was extracted from the synthetic seismic records of Figures 4, 5, and 6 along the top and bottom of the channel reservoir. According to the differences in main frequency and interference, the contrast diagram of the average amplitude extracted from the synthetic seismic records of channel reservoir with and without interference at different main frequencies was formed (Figure 11-13). In Figures 11-13, the black line and the blue line represented the average amplitude extracted from the channel reservoir without and with interference, respectively. Thus, interference sometimes had great influences on the average amplitude. For example, between the channel numbers of 50 and 60 in Figure 11(b), the original nonchannel average amplitude, which was nearly 0 , exceeded 1.5 


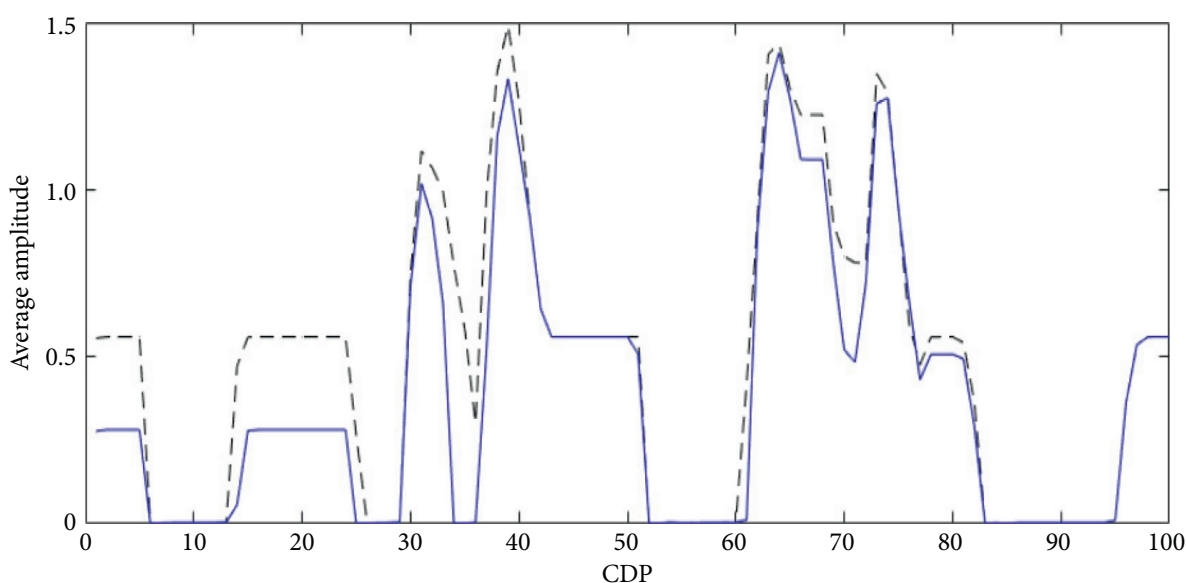

(a)

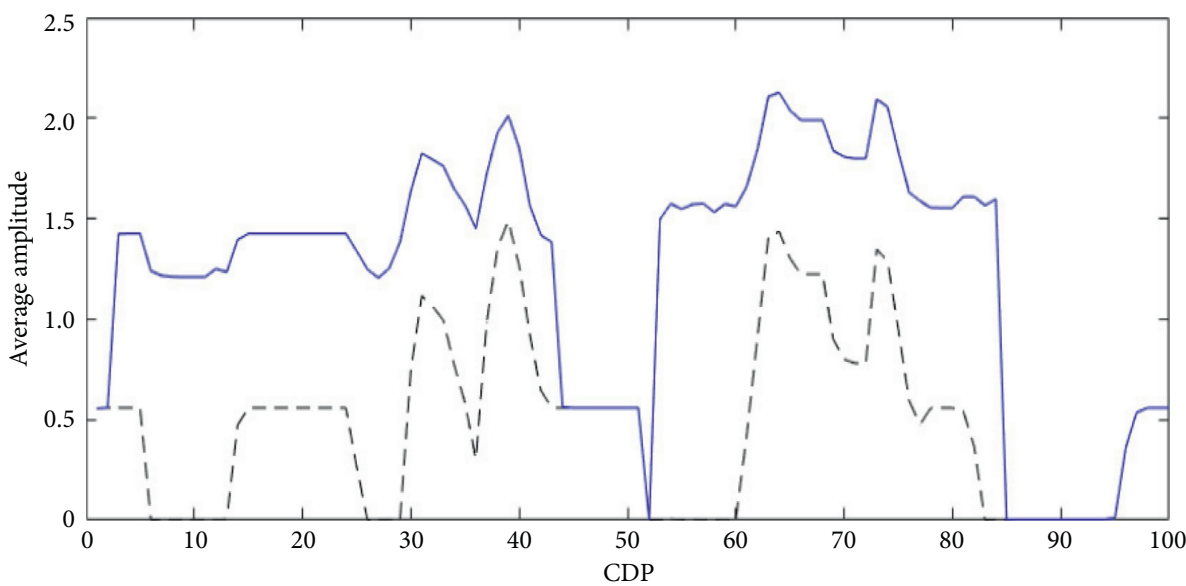

(b)

Figure 11: Contrast diagram of the average amplitude extracted from the synthetic seismic records of channel reservoir with and without interference at $20 \mathrm{~Hz}$. (a) Noninterference and upper interference. (b) Noninterference and lower interference.

under interference that was equivalent to the average amplitude of the nearby channel. This could easily bring misjudgment to the channel reservoir interpretation. Near the channel number of 10 in Figure 13(a), the original channel amplitude was roughly 0.4 , which became nearly 0 under interference. From the above-mentioned information, it can be suggested that the seismic attributes extracted from channel reservoir with upper and lower interference layers by the existing time window control theory may be greatly different from those extracted from channel reservoir without upper or lower interference layers, which will bring misjudgment to the channel reservoir interpretation and great risks to the channel oil and gas reservoir exploration. Therefore, it was very important to develop a time window control theory for attribute extraction favorable for channel reservoir prediction.

In order to obtain the research conclusions about the time window control theory, an interference layer with a thickness equivalent to the composite thickness $(35 \mathrm{~m})$ of sand and mud interstratification (Figure 14) and a target layer with a thickness equivalent to the composite thickness $(80 \mathrm{~m})$ of sand and mud sediments (Figure 15) were designed. First of all, it is necessary to obtain the imaging data for the interference layer and target layer. To meet this end, the geological models, including either the interference layer (Figure 16) or the target layer (Figure 17), were designed. These models were then imposed by the Ricker wavelet with the main frequency of $25 \mathrm{~Hz}$ to yield the synthetic seismic records in Figure 18 and 19, where there were a red arrow and a blue arrow. The positions corresponding to the arrows were the time when the seismic waves propagated to the top and bottom interfaces. The time when the seismic waves propagated to the top and bottom of geological models in Figures 16 and 17 was about $46 \mathrm{~ms} /$ $65 \mathrm{~ms}$ and $46 \mathrm{~ms} / 87 \mathrm{~ms}$, respectively. Suppose that there was an imaginary spring between the target layer and the interference layer. The target layer was fixed to allow the movements of the interference layer in two directions. One was the upward movement (as shown in Figure 20(a), the interference layer gradually moved upward under the action of the spring in the middle), and the other was the downward movement (as shown in Figure 20(b), the interference layer gradually moved downward under the action of the spring in the middle). Based on the time window of channel reservoir 


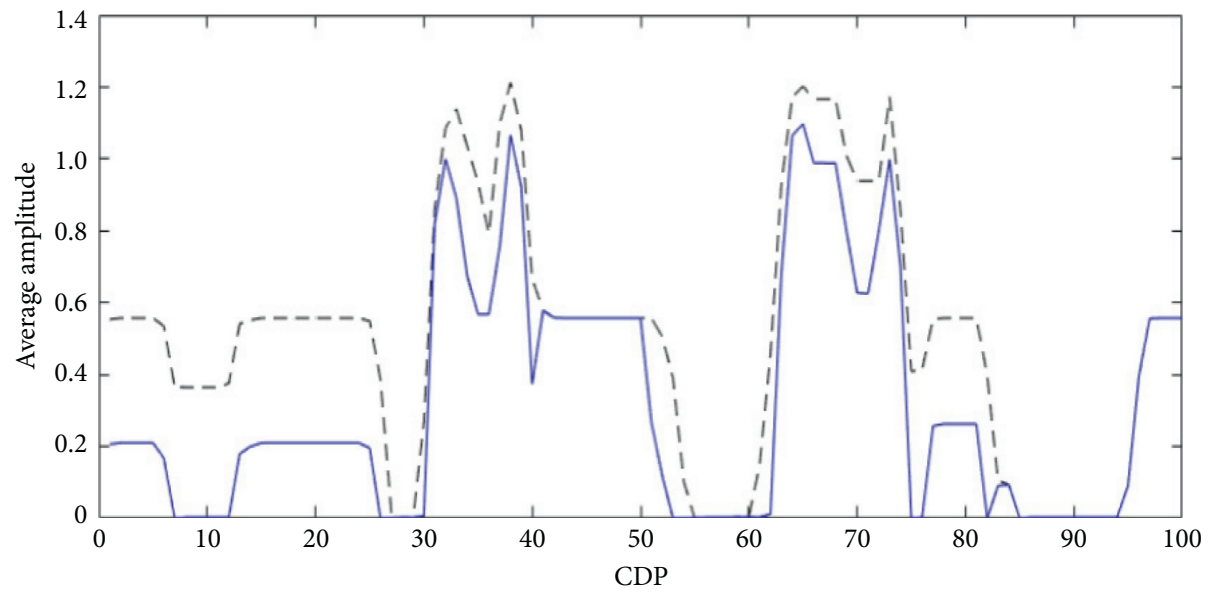

(a)

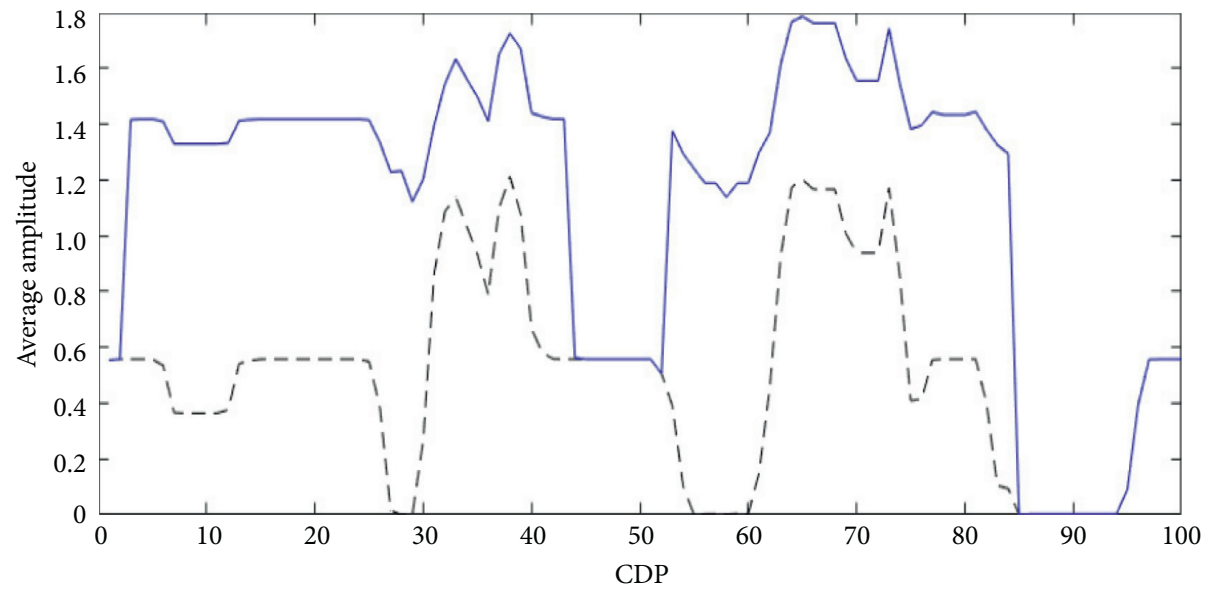

(b)

FIgURE 12: Contrast diagram of the average amplitude extracted from the synthetic seismic records of channel reservoir with and without interference at $30 \mathrm{~Hz}$. (a) Noninterference and upper interference. (b) Noninterference and lower interference.

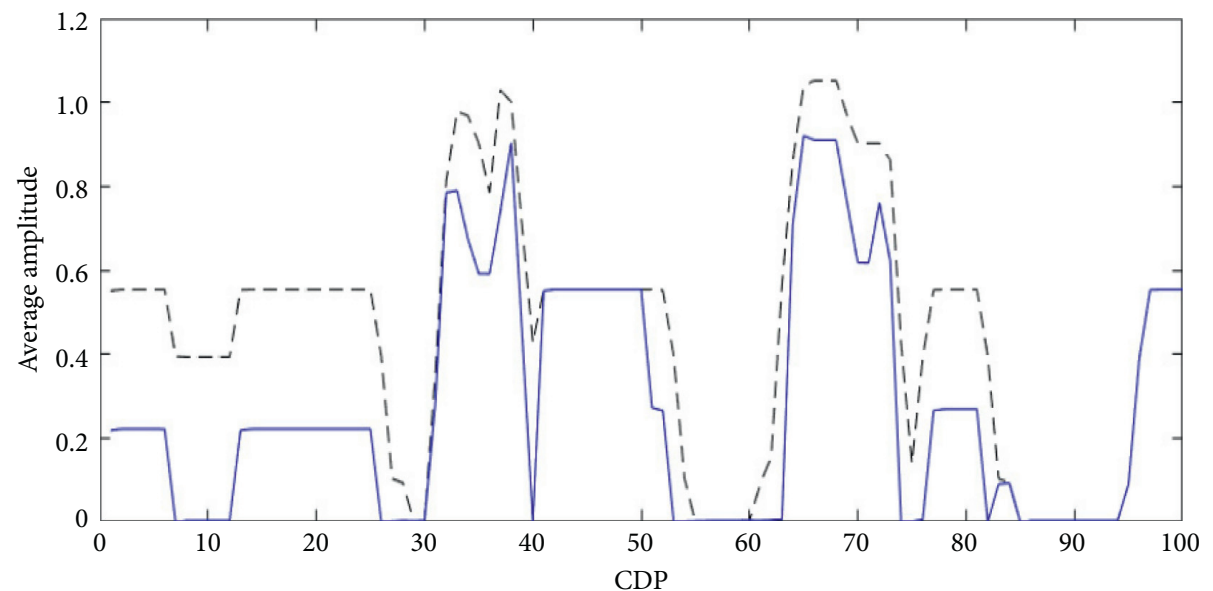

(a)

Figure 13: Continued. 


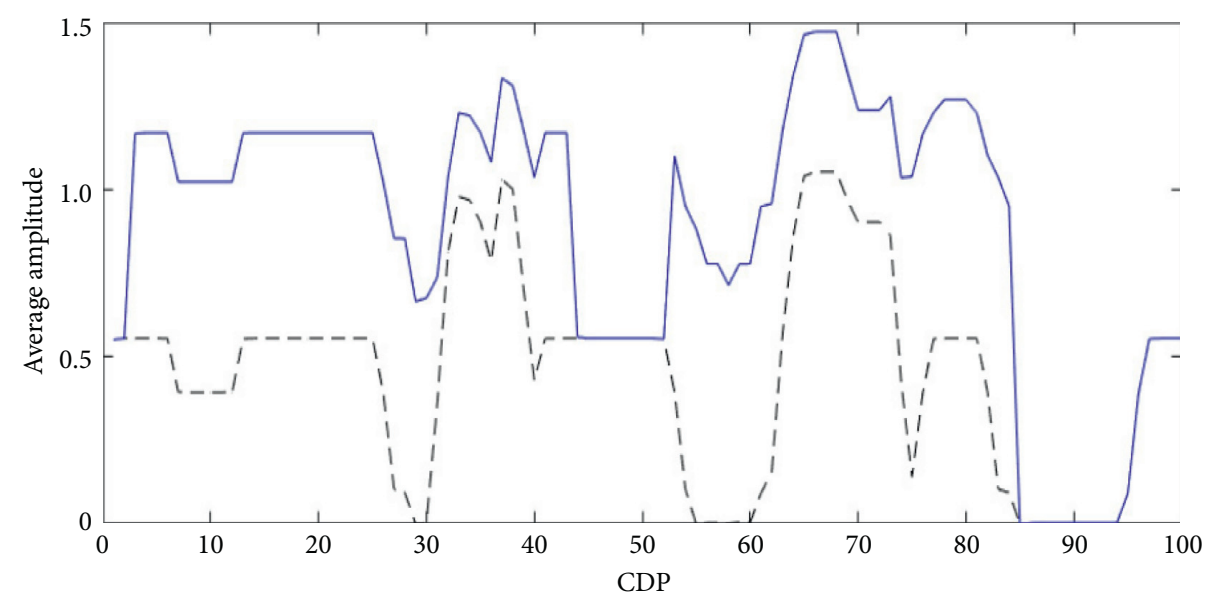

(b)

FIGURE 13: Contrast diagram of the average amplitude extracted from the synthetic seismic records of channel reservoir with and without interference at $40 \mathrm{~Hz}$. (a) Noninterference and upper interference. (b) Noninterference and lower interference.

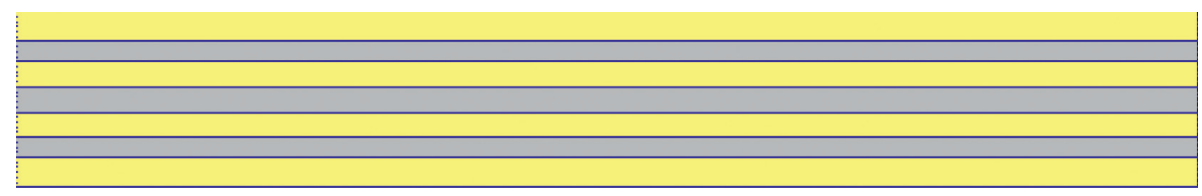

FIgURE 14: Interference layer with a thickness of $35 \mathrm{~m}$.

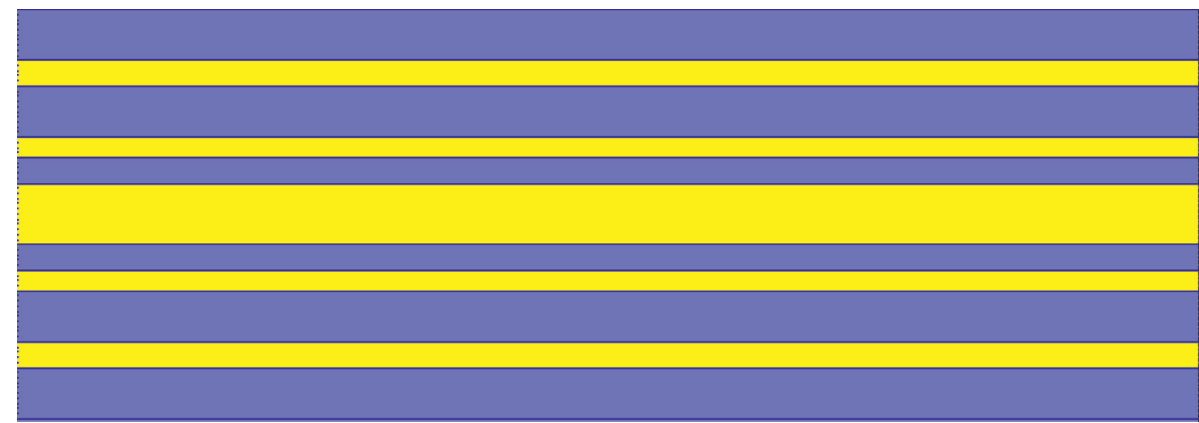

Figure 15: Target layer with a thickness of $80 \mathrm{~m}$.

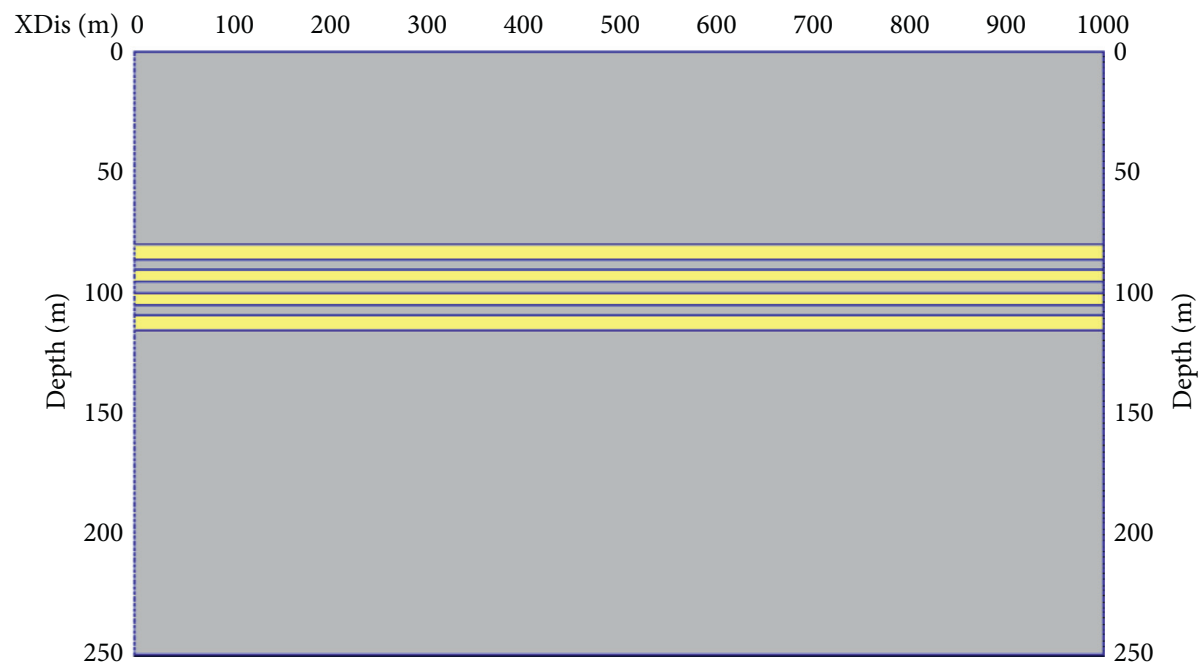

FIGURE 16: Geological model containing only the interference layer. 


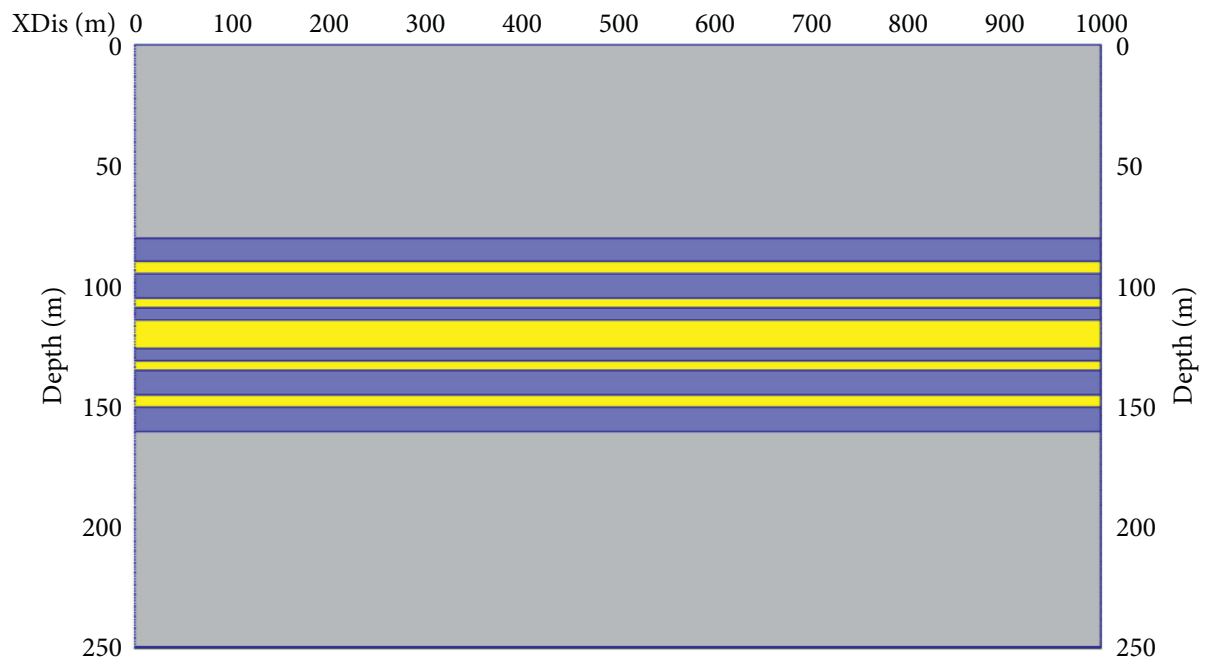

FIgURE 17: Geological model containing only the target layer.

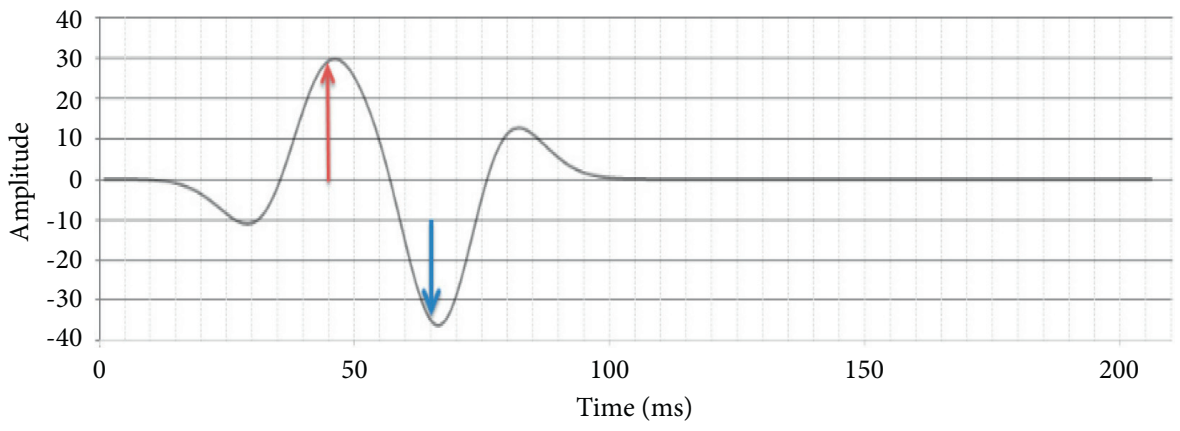

Figure 18: Synthetic seismic records obtained based on Figure 16.

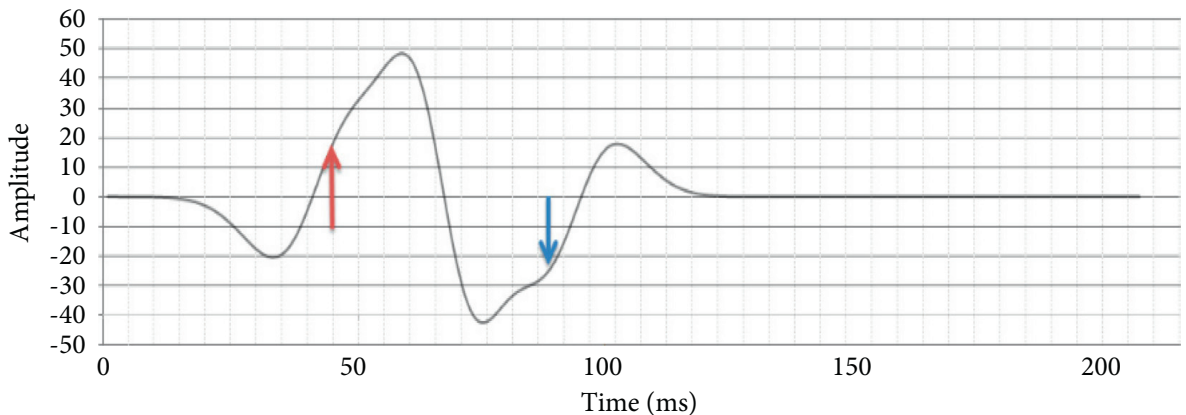

FIGURE 19: Synthetic seismic records obtained based on Figure 17.

top and bottom, the comparison between the waveform of interference layer moving upward or downward and the waveform without interference was shown in Figure 21. The light blue area and the red area are highlighted in Figure 21. Within the red area, there may be large differences in waveforms. Within the area outside the red area contained in the light blue area, there were fewer differences in waveforms caused by interference than those in the red area. According to the differences in waveforms, the light blue area was the maximum interference area, and the red area was the main interference area. The length of the blue area and the red area was roughly $35 \mathrm{~ms}$ and $15 \mathrm{~ms}$, respectively. Through comparison between Figure 21 and Table 4, the maximum interference area and main interference area were close to half of the apparent major period and apparent period corresponding to $25 \mathrm{~Hz}$, respectively. Further analysis of Figure 21 showed that when the distance between the different interference layers and the target layers was further increased, there was a growing similarity between the waveforms of the target layers and the waveforms without interference. The waveforms of the target layers were basically consistent with the waveforms without interference after the distance 


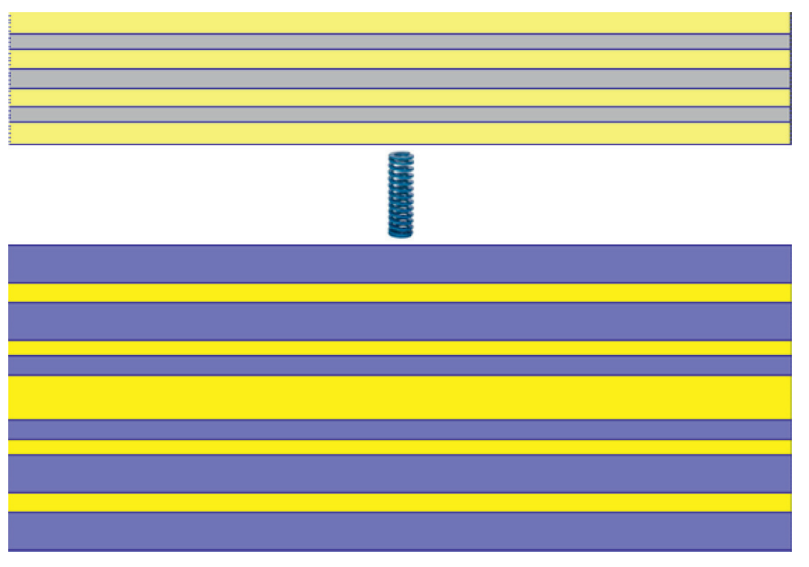

(a)

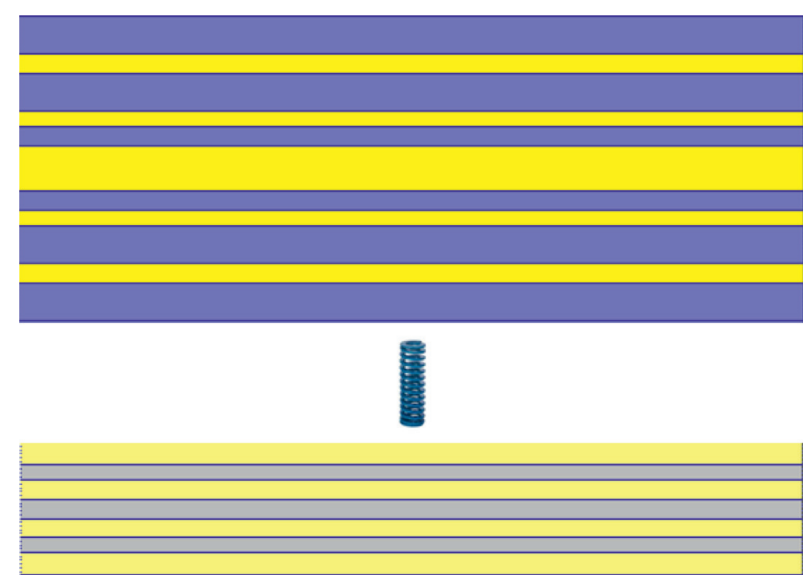

(b)

Figure 20: Schematic diagram of the model movement. (a) Upward movement of the interference layer. (b) Downward movement of the interference layer.

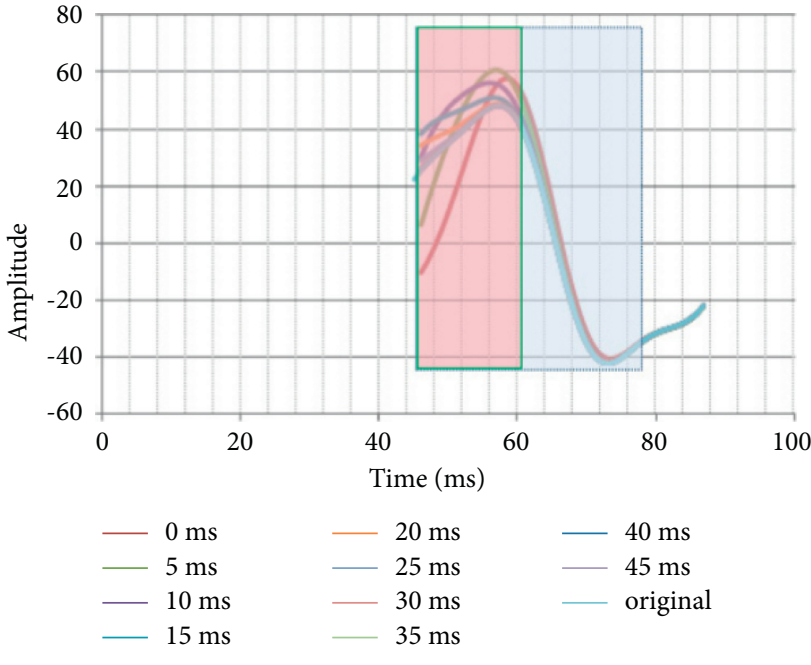

(a)

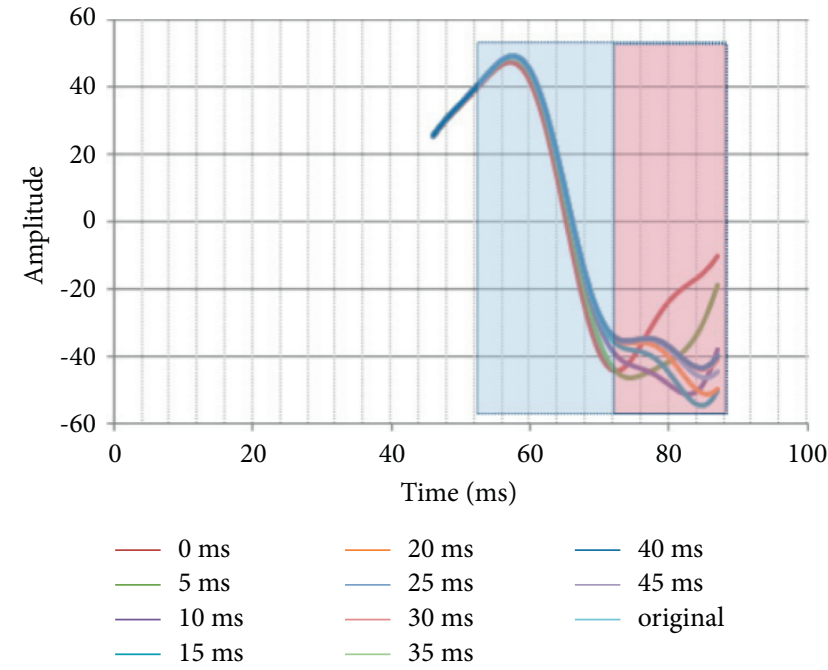

(b)

FIGURE 21: Comparison between waveforms of the target layers at different offset time. (a) Upward movement of the interference layer. (b) Downward movement of the interference layer.

between the interference layers and the target layers increases to a certain extent. This showed that there was a negative correlation between the degree of interference of interference layers on the target layers and the homogeneous formation thickness between the two. The greater the homogeneous formation thickness, the smaller the degree of interference; the smaller the homogeneous formation thickness, the greater the degree of interference. In addition, there was a negative correlation between the degree of interference of interference layers on the maximum interference area and main interference area of the target layers and the main frequency of seismic wavelet. The higher the main frequency of seismic wavelet, the smaller the maximum interference area and main interference area of the target layers; the lower the main frequency of seismic wavelet, the larger the maximum interference area and main interference area of the target layers. In the seismic attribute extraction, it was hoped that the extracted seismic attributes were an authentic reflection of the channel reservoir. So the maximum interference area, especially the main interference area, should be avoided as far as possible. That is, the imaging outside the interference area should be used to study the channel reservoir interpretation.

On the basis of the above research, a time window control theory that better illustrates the channel characteristics was proposed. The main contents of the time window control theory of channel interpretation: the time window for seismic attribute extraction should generally avoid the interference area (about half of $P_{\mathrm{AM}}$ ) as far as possible, that is, the time window value should be considered from at least the bottom of the upper interference area to at most the top of the lower interference area. When the 
thickness of channel reservoir is small, the maximum interference area (about half of $P_{\mathrm{A}}$ ) should also be avoided as far as possible. That is, the time window value is considered from at least the bottom of the upper maximum interference area to at most the top of the maximum interference area, especially the maximum interference area (about half of $P_{\mathrm{A}}$ ). Via exemption from the influence of upper and lower interference layers on the extraction of seismic attributes, the extracted seismic attributes can be used to better predict and analyze the reservoir channel changes.

\section{Conclusion}

The following conclusions were drawn based on the above research:

(1) The upper and lower interference layers in the channel reservoir have an influence on the imaging of the channel reservoir. The interference area can be divided into maximum interference area and main interference area depending on the degree of influence.

(2) When the interference layers above and below the channel reservoir are the same, different main frequencies of seismic wavelet lead to different sizes of interference area. The lower the main frequency of seismic wavelet, the larger the maximum interference area and main interference area affecting the imaging of channel reservoir; the higher the main frequency of seismic wavelet, the smaller the maximum interference area and main interference area affecting the imaging of channel reservoir.

(3) An applicable time window control theory for channel reservoir prediction was proposed. The theory clarifies that the time window for extracting seismic attributes should avoid the interference area (about half of $P_{A M}$ ), especially the maximum interference area (about half of $P_{A}$ ), so the extracted seismic attributes can be used to better predict and analyze the reservoir channel changes.

(4) When using the time window control theory of channel interpretation, the size of time window is generally set according to $P_{A M}$ and $P_{A}$. In this way, the time window control theory of channel interpretation proposed in this paper is applicable to the cases where the propagation time of seismic wave in the reservoir section is greater than $P_{A}$. This paper does not elaborate on such cases due to space limitations; however, this paper can serve as a reference to set up the time window in such cases.

\section{Data Availability}

The data used or analyzed during the current study are available from the corresponding author upon reasonable request.

\section{Conflicts of Interest}

The authors declare no conflicts of interest.

\section{Acknowledgments}

This research was supported by the Open Fund (CCL2020RCPS0416RQN) of the National Engineering Laboratory for Offshore Oil Exploration.

\section{References}

[1] D. C. Sather, "Importance of fluvial processes and related reservoir deposits," Journal of Petroleum Technology, vol. 45, no. 04 , pp. 368-377, 1993.

[2] W. Zhao, "The time-lapse seismic reservoir monitoring technology," Acceptance Report of National Advanced Technology Research and Development Projects, 2006.

[3] W. A. Wescott and P. J. Boucher, "Imaging submarine channels in the western Nile Delta and interpreting their paleohydraulic characteristics from 3-D seismic," The Leading Edge, vol. 19, no. 6, pp. 580-591, 2000.

[4] J. Xu, N. Dong, J. R. Ning, Y. G. Zhang, X. Y. Zhou, and G. Xu, "Sedimentary facies prediction of braided channel of the third member of shihezi formation in daniudi garfield, ordos basin," Lithologic Reservoirs, vol. 23, no. 2, pp. 90-94+132, 2011.

[5] Y. L. Zhang, F. Ding, C. Yin, G Hu, T. Fan, and X. Zhang, "The identification of fluvial sand-body superimposed area based on seismic waveform structure attributes," Acta Petrolei Sinica, vol. 39, no. 7, pp. 792-801, 2018.

[6] X. Y. Fan, G. Q. Xue, B. Liu, H. Yintao, X. Qi, and L. Weicai, "Recognition of single channel sandbody of meandering river with logging-seismic combination," Xinjing Petroleum Geology, vol. 40, no. 02, pp. 106-112, 2019.

[7] J. Liu, Z. T. Yang, and Q. W. Shuai, "Seismic coherence volume technique in river channel prediction," Journal of Yangtze University (Nat Sci Edit), vol. 7, no. 2, pp. 195-197, 2010.

[8] C. Zhou, C. Zhao, and W. Xiang, "Stratigraphic channel recognition and carving based on seismic attributes," Regional Governance, vol. 000, no. 42, pp. 177-179, 2019.

[9] R. R. Ray, K. Laughlin, P. Garossino, and G. Partyka, Spectral Decomposition Applied to 3-D, American Association of Petroleum Geologists, Geologists, Tulsa, OK, USA, 2002, http:// explorer.aapg.org/story/articleid/46838/spectral-decompapplied-to-3-d.

[10] S. R. Wang, S. P. Wang, B. R. Di, D.-Z. Ren, Z.-G. Wang, and D.-L. Lu, "Prediction of channel sand body based on seismic attributes," Oil Geophysical Prospecting, vol. 44, no. 3, pp. 304-313, 2009.

[11] Z. L. Yang, H. Q. Liu, and X. M. Sha, "Integrating seismic structure information and attribute information to characterize continental lake basin sedimentary system," Oil Geophysical Prospecting, vol. 52, no. 1, pp. 138-145, 2017.

[12] N. Li, Z. F. Liu, D. S. Yang, Z. S. Chen, and S. Z. Ying, "Application of comprehensive seismic attributes analysis technology in fine channel characterization," China Offshore Oil and Gas, vol. 32, no. 1, pp. 66-73, 2020.

[13] Z. Q. Song, "Prediction of the channel sand body by post-stack seismic inversion Technique," Petroleum Geology \& Oilfield Development in Daqing, vol. 37, no. 4, pp. 151-156, 2018.

[14] X. Bao, L. H. Suzhou and B. Liang, Research on Reservoir Evaluation Based on Prestack Seismic Data, Jiangsu Oilfield Scientific Research Report, Yangzhou, China, 2010.

[15] Y. Jiang, L. Zhang, Z. Wei, and H. Zhiqiang, "Technology for prediction of underwater distributary channel reservoir and application in B structure, Xihu Sag," Offshore Oil, vol. 35, no. 2, pp. 35-39, 2015. 
[16] Z. L. Yang, X. M. Sha, and Z. G. Li, "Oil and gas detection technology and its application in lithologic trap oil and gas reservoir exploration," Natural Gas Geoscience, vol. 21, no. 5, pp. 822-827+874, 2010.

[17] C. Zhu, Q. S. Gong, and X. C. Meng, "Application of seismic attribute analysis in fan recognition," Journal of Oil and Gas Technology, vol. 33, no. 9, pp. 64-67, 2011.

[18] X. B. Peng, "Principles of seismic exploration," 2012, http:// wenku.baidu.com/view/9d13c468b84ae45c3b358c0e.html. 